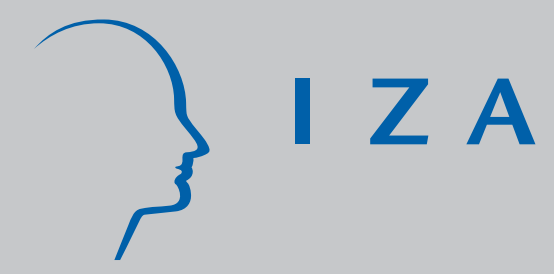

IZA DP No. 2416

Estimates of the Effect of Parents' Schooling on Children's Schooling Using Censored and Uncensored Samples

Monique de Haan

Erik Plug

November 2006 


\title{
Estimates of the Effect of Parents' Schooling on Children's Schooling Using Censored and Uncensored Samples
}

\author{
Monique de Haan \\ SCHOLAR, University of Amsterdam \\ Erik Plug \\ SCHOLAR, University of Amsterdam, \\ Tinbergen Institute and IZA Bonn
}

\author{
Discussion Paper No. 2416 \\ November 2006
}

\author{
IZA \\ P.O. Box 7240 \\ 53072 Bonn \\ Germany \\ Phone: +49-228-3894-0 \\ Fax: +49-228-3894-180 \\ E-mail: iza@iza.org
}

\begin{abstract}
Any opinions expressed here are those of the author(s) and not those of the institute. Research disseminated by IZA may include views on policy, but the institute itself takes no institutional policy positions.

The Institute for the Study of Labor (IZA) in Bonn is a local and virtual international research center and a place of communication between science, politics and business. IZA is an independent nonprofit company supported by Deutsche Post World Net. The center is associated with the University of Bonn and offers a stimulating research environment through its research networks, research support, and visitors and doctoral programs. IZA engages in (i) original and internationally competitive research in all fields of labor economics, (ii) development of policy concepts, and (iii) dissemination of research results and concepts to the interested public.
\end{abstract}

IZA Discussion Papers often represent preliminary work and are circulated to encourage discussion. Citation of such a paper should account for its provisional character. A revised version may be available directly from the author. 
IZA Discussion Paper No. 2416

November 2006

\section{ABSTRACT \\ Estimates of the Effect of Parents' Schooling on Children's Schooling Using Censored and Uncensored Samples ${ }^{*}$}

In this paper we estimate the impact of parental schooling on child schooling, focus on the problem that children who are still in school constitute censored observations, and evaluate three solutions to it: maximum likelihood approach, replacement of observed with expected years of schooling, and elimination of all school-aged children. Plug (2004) - a recent mobility study that relies on censored data - serves as an illustration. With updated and uncensored versions of previous samples, we re-examine Plug's estimates and test how the three correction methods deal with censored observations. The one that treats parental expectations as if they were realizations seems to fix the censoring problem quite well.

JEL Classification: $\quad$ 12, J62, C34

Keywords: intergenerational mobility of education, censored observations

Corresponding author:

Erik Plug

Department of Economics

University of Amsterdam

Roetersstraat 11

1018 WB Amsterdam

The Netherlands

E-mail: e.j.s.plug@uva.nl

\footnotetext{
* The authors thank Reyn van Ewijk, Hessel Oosterbeek and Auke IJsselstein for their helpful comments. They further thank the Dutch National Science Foundation for its support under VIDI Grant 452.03.309. Support for collection and dissemination of data from the Wisconsin Longitudinal Study has been provided by the National Institute on Aging (AG-9775), the National Science Foundation (SBR-9320660), the Spencer Foundation, and the Center for Demography and Ecology and the Vilas Estate Trust at the University of Wisconsin-Madison. Data and documentation from the Wisconsin Longitudinal Study are available at http://dpls.dacc.wisc.edu/WLS/wlsarch.htm. Copies of the computer programs used to generate the results presented in this paper are available upon request from the authors.
} 


\section{Introduction}

Recent intergenerational mobility studies that make a distinction between causation and selection - exemplified by Jere Behrman and Mark Rosenzweig (2002), Erik Plug (2004) and Sandra Black, Paul Devereux and Kjell Salvanes (2005)rely on samples in which information on the child's completed schooling is not always available. Unfortunately, the solutions offered to handle censored samples may lead to biased estimates when the assumptions on which they are based are incorrect. Behrman and Rosenzweig (henceforth often BR), for example, suggest to replace incomplete observations with parental expectations about their child's completed schooling, which is by no means a trivial solution (Kate Antonovics and Arthur Goldberger 2005). Plug tackles the censoring problem with a standard censored regression model, but ignores the possibility that the maximum likelihood estimates are only unbiased if the error distribution is correctly specified, which can be quite problematic in practice (Goldberger 1983; Kenneth Chay and James Powell 2001). And Black, Devereux and Salvanes (henceforth often BDS) decide to eliminate all of the school-going aged children from their sample, and introduce the risk of sample selection bias.

But if much of the recent mobility literature estimate parental schooling effects on censored samples using correction methods that may not always work, shouldn't we worry that previous results miss the true impact of parental schooling on child schooling? In this paper we address this concern and re-examine Plug's estimates using the standard censored regression model as well as the other two correction methods to one particular data set: the most recent version of the Wisconsin Longitudinal Study (henceforth often WLS).

The WLS collects information on a large group of students who graduated from Wisconsin high schools in 1957. In 1975, 1992 and 2004 the same students were contacted again and asked about their children's schooling. The questions cover three different school stages. In 1975 most children are still in school: the sample includes information on expected schooling. In 1992 the same children are about to complete school: the sample is a censored sample. In 2004 all children have passed their school-going age: the sample contains information on completed schooling.

Our contributions are twofold. First, we present new and better estimates of the intergenerational mobility of schooling. We use own birth children and adoptees to investigate how much inherited abilities contribute to the impact of parental schooling. With updated 2004 samples, we estimate the ultimate mobility models in which censored observations are absent. And second, we examine the validity of the proposed solutions to deal with the problem of censored data. With the 1975 and 1992 samples, we estimate the impact of parental schooling on children's schooling applying the various procedures to correct for censored observations and use the difference between ultimate and corrected mobility estimates as a validity indicator.

This paper continues as follows. Section 2 models the intergenerational mobility of schooling, focuses on the problem that children who are still in school generate censored observations, and provides some intuition of the various solu- 
tions to it. Section 3 provides a brief description of the Wisconsin Longitudinal Survey. Section 4 presents and compares the parameter estimates. Section 5 concludes.

\section{Mobility models using censored data}

Much of recent work on intergenerational schooling mobility has concentrated on estimating a version of the following model

$$
S_{t}=\delta S_{t-1}+\epsilon_{t}
$$

where $t$ is a generation index, $S_{t}$ and $S_{t-1}$ represent the schooling of child and parent, usually measured as the number of years of completed schooling, and $\epsilon_{t}$ is a child-specific characteristic. The mobility parameter $\delta$ measures the association between the schooling of parent and child. With information on $S_{t}$ and $S_{t-1}$, the least-squares estimator is defined as

$$
\operatorname{plim} \delta_{O L S}=\operatorname{cov}\left(S_{t}, S_{t-1}\right) / \operatorname{var}\left(S_{t-1}\right)=\delta .
$$

A well-known problem in analyzing intergenerational schooling mobility is that information on the child's completed schooling is not always available. Some children are still in school at the time data are collected and create censored observations. To accommodate censored observations, the intergenerational schooling model needs to be rewritten as

$$
S_{t}^{c}=\left\{\begin{array}{cl}
S_{t}^{c}=S_{t} & \text { if } d_{t}=0, \\
S_{t}^{c}<S_{t} & \text { if } d_{t}=1,
\end{array}\right.
$$

where $S_{t}^{c}$ represents the child's years of schooling observed in the censored sample, and $d_{t}$ denotes whether observations are censored $\left(d_{t}=1\right)$ or not $\left(d_{t}=0\right)$. If we would ignore censoring, and treat the children's observed years of schooling as if it were their completed years, the estimation of $S_{t}^{c}$ on $S_{t-1}$ using ordinary least squares gives us a mobility parameter that is too low. ${ }^{1}$ The intuition is as follows. Since more schooled children (with more schooled parents) are more likely to be censored and observed years are smaller than or equal to the completed years, we know that observed years of schooling covary less with parental years of schooling $\left(\operatorname{cov}\left(S_{t}^{c}, S_{t-1}\right) \leq \operatorname{cov}\left(S_{t}, S_{t-1}\right)\right)$. When we now apply least squares to estimate the model

$$
S_{t}^{c}=\delta^{c} S_{t-1}+\epsilon_{t}^{c},
$$

it follows naturally that the corresponding least squares estimator is biased toward zero, as

$$
\operatorname{plim} \delta_{O L S}^{c}=\operatorname{cov}\left(S_{t}^{c}, S_{t-1}\right) / \operatorname{var}\left(S_{t-1}\right) \leq \operatorname{cov}\left(S_{t}, S_{t-1}\right) / \operatorname{var}\left(S_{t-1}\right)=\delta .
$$

\footnotetext{
${ }^{1}$ Steven Haider and Gary Solon (2006) examine a related problem within an intergenerational income mobility context. They test how intergenerational income estimates are affected by the age at which offspring's income is observed, and find that mobility estimates are biased downwards when the children's income is measured too early in life.
} 
Recent work on intergenerational mobility of schooling has taken three approaches to tackle the censoring problem: maximum likelihood approach, replacement of observed with expected years of schooling, and elimination of all school-aged children. Below we shortly discuss the different approaches.

\section{A censored regression model}

Plug (2004) exploits the 1992 wave of the WLS to estimate the effect of fathers and mothers schooling on child's schooling using samples of biological and adopted children. In 1992, however, many children have not yet finished their schooling (about $25 \%$ of the biological children and $40 \%$ of the adopted children). As we already mentioned, not taking censoring into account gives inconsistent estimates. Plug therefore uses a censored regression model, one of the standard procedures for handling censored observations. Assuming the conditional distribution of $\epsilon$ is normally distributed with homoskedastic errors the likelihood function is

$$
L(\theta)=\prod_{i=1}^{N}\left[\phi\left(S_{t} \mid S_{t-1}, \theta\right)\right]^{1-d_{t}}\left[1-\Phi\left(S_{t}^{c} \mid S_{t-1}, \theta\right)\right]^{d_{t}},
$$

where $\phi$ and $\Phi$ represent normal density and distribution functions, $\theta$ are the distribution parameters that include $\delta$, and $i$ indexes the family in which the child is born and raised. Maximization of (6) yields a consistent estimator of $\delta$, unless the error distribution is incorrectly specified, being non-normally distributed or having heteroskedastic errors of unknown form.

\section{Inserting parental expectations for children still in school}

Behrman and Rosenzweig (2002) employ a mail survey -issued in 1994- to collect information on the families of identical twins born between 1936 and 1955, all drawn from the Minnesota Twin Registry (MTR). The survey contains information on the schooling of the twins, their parents and children, including information on expected schooling for children who had not completed their schooling yet; this is the case for more than $50 \%$ of their sample. ${ }^{2}$

BR propose to replace their censored observations with parental expectations and treat these expectations as if they were school realizations for children with unfinished schooling. This gives the following school variable for the child

$$
\widetilde{S}_{t}=\left\{\begin{array}{lll}
S_{t} & \text { if } & d_{t}=0 \\
S_{t}^{e} & \text { if } & d_{t}=1
\end{array}\right.
$$

where $S_{t}^{e}$ represents the school level the parent expects her child to complete. Suppose we model parental expectations about their children's completed years

\footnotetext{
${ }^{2}$ The American Economic Review provides data and programmes for replication purposes online. From this source we have extracted the twin sample using data and programmes of Antonovics and Goldberger (2005). We are able to trace 844 monozygotic twin parents with children. Of these 844 children, 428 are still in school in 1994.
} 
of schooling as follows

$$
S_{t}^{e}=S_{t}+\eta_{t}
$$

where $\eta_{t}$ is the error parents make in predicting their child's completed schooling. Combining (1), (7) and (8) gives

$$
\widetilde{S}_{t}=\delta S_{t-1}+d_{t} \eta_{t}+\epsilon_{t} .
$$

Applying least squares to the bivariate regression of $\widetilde{S}_{t}$ on $S_{t-1}$ gives us the following probability limit of the slope coefficient

$$
\operatorname{plim} \widetilde{\delta}_{O L S}=\operatorname{cov}\left(\widetilde{S}_{t}, S_{t-1}\right) / \operatorname{var}\left(S_{t-1}\right)=\delta+\operatorname{cov}\left(d_{t} \eta_{t}, S_{t-1}\right) / \operatorname{var}\left(S_{t-1}\right) .
$$

Only if $\operatorname{cov}\left(d_{t} \eta_{t}, S_{t-1}\right)$ equals 0 , BR's original solution produces an unbiased estimate of $\delta$. If parents form accurate expectations independent of their background this condition will always hold. If not, the validity of the method will depend on how much the prediction error correlates with parental education and on the number of censored observations.

\section{Eliminating all school-going aged children}

Black, Devereux and Salvanes (2005) estimate the effect of parental schooling on child schooling using a reform in compulsory schooling in Norway during the sixties and early seventies to draw causal inferences. Because BDS focus on relatively young parents - only those between 42 and 53 years old are affected by the reform- many children have not finished their schooling yet by the time they appear in their sample. They take account of the censoring problem by eliminating all children younger than age 25 .

Many of these children are likely to have parents who were very young when they were born. DBS therefore run the risk of introducing sample selection bias when they reduce their sample. The argument is that censoring is not random but related to observed and unobserved parental characteristics, and that the corresponding estimate of the effect of parental schooling using the reduced sample can be biased.

\section{Data}

Our analysis employs the Wisconsin Longitudinal Study (WLS) of 10,317 randomly sampled graduates from Wisconsin high schools in 1957. After the initial wave of data collection, primary respondents were re-interviewed in 1975, 1992 and 2004. Together with their parents' interview of 1964, these waves provide information on, among others, educational attainment of the original graduates, their parents and children. The original sample is broadly representative for white men and women, who have completed at least twelve years of schooling. For more detailed information on the WLS we refer to William Sewell, Robert Hauser, Kirsten Springer and Taissa Hauser (2004) and Erica Wollmering (2006) and the references therein. 
In this paper we use all three waves and exploit those questions that are targeted at the educational attainment of the respondents' children. In 1975 children are still in school and questions are asked to elicit parental expectations. ${ }^{3}$ In 1992 children are about to complete or just completed their schooling and information is collected on the highest grade of regular school ever attended; whether the highest grade is completed or not; and whether the highest grade is obtained during the survey year. In 2004 these children all finished their education, and respondents are asked to update their information regarding their children's completed schooling.

Our sample includes married respondents with children, who are observed in the years 1975, 1992 and 2004. In 2004 information is gathered from 7,265 of the 10,317 original respondents, of whom 5,630 are married and have children older than 12 in 1992. Of these 5,630 respondents 442 drop out because relevant schooling information of themselves, their spouses and children is missing. ${ }^{4}$ This leaves us with a sample of 5,188 respondents having 14,524 own birth children and 520 adopted children. ${ }^{5}$ Summary statistics on own birth children and adoptees appear in Table 1.

\section{Results}

Table 2 presents estimates that come from our child-parent schooling regressions run on uncensored and censored samples of own-birth children and their parents. All regressions include individual controls for the child's age and gender. These parameters are not reported. ${ }^{6}$

In the first three columns we report estimates using the completed school measures as recorded in the 2004 sample. In columns (1) and (2) the mother's and father's schooling measures are included as separate regressors. We find that more schooled parents have more schooled children, and that more schooled mothers matter more than more schooled fathers. In column (3) the mother's and father's schooling measures are included simultaneously to control for assortative mating effects. We still find that more schooled parents get more schooled children, but that fathers and mothers now contribute equally to their offspring.

\footnotetext{
${ }^{3}$ Parental expectations are expressed in levels. We convert level into years as follows: less than high school...10; high school graduate...12; technical and vocational education...13; some college...14.5; college graduate..16; M.A. or M.S. degree...18; Law degree, M.D., D.D.S., D.V.M. degree. .19; Ph.D...20.

${ }^{4}$ For some children who finished schooling in 1992, reported years of schooling in 2004 differs from years of schooling reported in 1992. For these observations we replace reported schooling in 1992 and 2004 by the maximum of the two. This is done for 487 own birth children and 39 adoptees.

${ }^{5}$ Note that in 1975 respondents are asked to express their school expectations for only one of their children. This means that the censoring analysis in which we replace censored with expected school measures relies on a much smaller sample, consisting of 4,097 own-birth and 52 adopted children.

${ }^{6}$ The estimations use all children, including all children raised in one family. With multiple family observations, standard errors are not independent within families and are biased downwards. We therefore estimate the model with clustered error terms to control for correlation within families.
} 
In the second three columns we estimate the same three equations using the observed school measures as recorded in the 1992 sample. With data that are partly censored we find, as expected, that all parental schooling estimates fall. It is clear that these estimates are biased. The last three columns, in which we express the difference between mobility estimates run on the censored and uncensored samples, indicate that the downward bias caused by the censoring is statistically significant and varies between the 6 and 16 percent. ${ }^{7}$

In the next three panels we report the estimates using alternative approaches to tackle the censoring problem: maximum likelihood approach, replacement of observed with expected years of schooling, and elimination of all school-aged children. We find that the corrections do not affect our results qualitatively. In all three panels the estimates reported in columns (4), (5) and (6) show that more schooled parents get more schooled children and that mothers only matter more when parental schooling estimates include assortative mating effects. But we do find that the corrections affect our results quantitatively. When compared to the uncorrected regression results using the censored sample, all three approaches remove the downward bias and give us -as they should- higher mobility estimates. When compared to those estimates obtained using the ultimate uncensored sample, the estimated differences in columns (7), (8) and (9) indicate that especially maximum likelihood and elimination approaches lead to mobility estimates that are too high. Instead of providing consistent estimates, these two censoring corrections cause an upward bias that is statistically significant and varies between the 6 and 21 percent. The medicine appears to be no better than the malady. The approach to treat parental expectations for young children as if they were realizations of completed schooling, however, does much better. The bias is at most 4 percent and never statistically significant.

\section{Adoption results}

Recall that all the positive mobility estimates reported in Table 2 include the contribution of inherited abilities to intergenerational schooling transfers. To get rid of the effects caused by the parents' genes, we run our child-parent schooling regressions on samples of adoptees and their adoptive parents. This is done in Table 3 which has the same format as Table 2.

In columns (1), (2) and (3) the results using the uncensored sample of adoptees are shown. We find that all the estimated effects of parental schooling drop when we move from own-birth children to adoptees. This is consistent with the idea that part of the child's schooling is inherited. In column (3) we take the impact of the marriage partner into account, and find that the estimates fall only little for fathers, but much more for mothers. The maternal schooling effect reduces to 0.08 and lacks statistical significance, while the paternal schooling effect remains much larger in magnitude: 0.22 and 0.19 with or without taking into account the effect of his marriage partner. These findings are, as such, fully

\footnotetext{
${ }^{7}$ The previous schooling models are estimated combining both WLS samples where all coefficients vary by sample status. The interacted schooling estimate represents the absolute difference between mobility parameters.
} 
in line with those reported in Plug (2004) but also in Behrman and Rosenzweig (2002, 2005) and Björklund, Lindahl and Plug (2006).

In columns (4), (5) and (6) of the first panel we see that the estimated effects remain qualitatively very similar, except that they are all smaller than the corresponding point estimates in the first three columns. This is not unexpected when we switch from the uncensored to the censored adoption sample. The bias is bigger than in our previous samples and varies between 11 and 21 percent. Probably because of the smaller samples, the censoring bias is rather imprecisely estimated, and never statistically significant (see columns (7), (8) and (9)).

In the remaining panels we evaluate the various solutions to the censoring bias. Compared to the uncorrected regression results using the censored adoption sample the three approaches produce (almost always) higher mobility estimates and thus appear to remove the downward bias. Compared to the results in Table 2 the estimated impacts of parental schooling drop and inherited abilities and assortative mating seem to play a more important role for mothers than for fathers. There is one exception. In the last panel where we eliminate all school-going aged children, we obtain a coefficient on mother's schooling that is statistically significant and almost of the same size as the coefficient on father's schooling. ${ }^{8}$ In columns (7), (8) and (9) we report on the differences between the estimates using the three approaches and the estimates without censoring. These differences are larger than those differences reported in Table 2 using the sample of own-birth children. But since resulting differences are all statistically insignificant, it is difficult to draw firm conclusions about the validity of each solution.

\section{Can we treat parental expectations as realizations?}

While these adoption results are not informative about the preferred correction approach, our own-birth results suggest that parental expectations fix the censoring problem quite well. ${ }^{9}$ This is by no means a trivial result. In a recent

\footnotetext{
${ }^{8}$ With the same correction applied to Norwegian data Black, Devereux and Salvanes (2005) also find a positive effect of mother's schooling. But unlike us, they find no effect of father's schooling.

${ }^{9}$ Two of the three correction methods, however, do not work. Both the maximum likelihood approach and the elimination approach produce mobility estimates that are too high. We can think of the following explanations. One likely candidate to explain the upward bias of the maximum likelihood approach would be a normality violation -the more appropriate distribution of the child's completed education is bimodal with peaks around 12 and 16 years. If we assume a bimodal distribution of years of schooling, our simulation results - not reported in the paper- bear out that the inconsistency of the maximum likelihood estimator is indeed positive when about 25 percent of the observations is right censored. Abbas Arabmazar and Peter Schmidt (1982) also investigate the inconsistency of the related Tobit estimator as a consequence of different non-normal distributions. They find, like we do, that the bias due to non-normality depends on the degree of censoring. They do, however, not investigate the consequences of a bimodal distribution. The other candidate to explain the inconsistencies caused by the elimination procedure would relate to the assumed linearity of the mobility specifications we estimate. If, for example, mobility is lower at the lower end of the distribution (Philip Oreopoulos, Marianne Page and Ann Huff Stevens 2006) the elimination of mostly children from higher educated parents would lead to an estimate of the mobility parameter
} 
paper Antonovics and Goldberger (2005 p.1739) express their doubt regarding this particular correction method. This subsection therefore performs additional robustness checks.

Figure 1 shows histograms of the difference between parental expectations and realizations separately for own birth children and adoptees. Although for more than 30 percent of the children parental expectations coincide with realizations, there is quite some variation in how well parents can predict their child's schooling. But if parents are not able to perfectly predict their child's education, why does the method work so well?

We already showed in Section 2 that parental expectations form an appropriate solution to the censoring problem if the number of censored observations $\left(d_{t}\right)$ and parental prediction errors $\left(\eta_{t}\right)$ do not depend on parental schooling and everything else that is correlated with it; that is,

$$
\operatorname{cov}\left(d_{t} \eta_{t}, S_{t-1}\right) / \operatorname{var}\left(S_{t-1}\right)=0 .
$$

This is an expression we can actually test. To see whether our results are sensitive to the number of censored observations, the quality of parental expectations, or both, we run least squares regressions of $d_{t} \eta_{t}$ on mother's and father's schooling on samples where we gradually increase the number of censored observations. We do this by calculating how many children would still be in school if we had observed them some years before 1992. For example, if a mother, who reports in 1992 that her child, born in 1967, completed 15 years of schooling, were interviewed in 1984 we recode the same child as being censored, assuming he/she left school in $1988(1967+6+15) \cdot{ }^{10}$

Table 4 contains the estimates of the effect on mother's and father's schooling on $d_{t} \eta_{t}$ for increasing numbers of censored observations, separately for own birth children and adoptees, with additional controls for age and gender of the child. The adoption parameters are reported, but not discussed because of sample size considerations. Up to censoring percentages of 40, we find that all the parental schooling estimates are statistically insignificant and virtually zero, confirming our baseline result that the replacement method yields consistent mobility estimates. Up to censoring percentages of 80 , the parental schooling effects are negative but small, and often statistically insignificant. The procedure to replace the censored observations with expectations is statistically rejected, but only at the margin. Only when the percentage of censored observations becomes very large, the corresponding method to adjust for censoring fails. The slopes are negative and statistically significant. Would we fully rely on parental predictions, the implication is that the corresponding intergenerational mobility estimates are biased downwards. ${ }^{11}$ The negative bias further suggests that expectations regress to the mean faster than realizations do.

\footnotetext{
that is too high.

${ }^{10}$ These calculations assume that children start school at age 6 and have uninterrupted school careers.

${ }^{11}$ When we treat all children with completed and uncompleted schooling as if they were censored observations, we find mobility estimates of 0.18 [0.02] and 0.23 [0.01] for mothers and fathers, respectively; with standard errors shown in brackets. Compared to the uncensored mobility results, these estimates are statistically but not substantially different, which is
} 
We conclude from all this that the replacement procedure is not as disconcerting as Antonovics and Goldberger say it is. Although parents cannot perfectly predict their child's schooling and the method fails when the number of censored observations becomes extremely large, the procedure still works when almost half of the censored observations is replaced with expectations (which more or less equals the replacement rate used in Behrman and Rosenzweig's study).

\section{Concluding remarks}

Recent mobility studies that make a distinction between causation and selection often rely on samples in which information on the child's completed schooling is not always available. Unfortunately, solutions offered to handle censored samples do not always work, and should be further scrutinized.

This is what we do in this paper. We first estimate the impact of mother's and father's schooling on child's schooling using censored and uncensored samples of own-birth children and adoptees, and then investigate the consequences of three different methods that deal with censored observations: maximum likelihood approach, replacement of observed with expected years of schooling and elimination of all school-aged children.

Our basic result is that, net of assortative mating effects, positive parental schooling effects fall only little for fathers, but much more for mothers when we move from uncensored samples of own-birth children to adoptees. This result appears to be fairly robust to the introduction of censored observations and the application of three correction methods. Parental schooling effects fall, but not by much, when mobility models are estimated on censored samples and rise, again not by much, when censored observations are tackled by either three correction methods. Of the three methods, the one that treats parental expectations as if they were realizations performs best. This result depends, however, on the degree of censoring. For samples that are largely incomplete the method does give a (negative) bias.

Having said this, let us take one step back and evaluate the mobility estimates we have found. Our results suggest that the mother's schooling has almost no impact on the schooling of her child, holding everything else (including unobserved ability factors of either mother or father) constant. Although these results are in contradiction with widely held wisdom, we are inclined to take them seriously. With censored twin samples using a correction method that apparently works, Behrman and Rosenzweig $(2002,2005)$ find rather small maternal treatment effects that are very similar to ours.

quite remarkable given that schooling expectations were already measured in 1975 when most children were still in primary school. 


\section{References}

Antonovics, Kate L., and Arthur S. Goldberger. 2005. Does Increasing Women's Schooling Raise the Schooling of the Next Generation? Comment. American Economic Review, 95(5):1738-1744.

Arabmazar, Abbas, and Peter Schmidt. 1982. An Investigation of the Robustness of the Tobit Estimator to Non-Normality. Econometrica, 50(4):10551064 .

Behrman, Jere R., and Mark R. Rosenzweig. 2002. Does Increasing Women's Schooling Raise the Schooling of the Next Generation? American Economic Review, 92(1):323-334.

Behrman, Jere R., and Mark R. Rosenzweig. 2005. Does Increasing Women's Schooling Raise the Schooling of the Next Generation? Reply. American Economic Review, 95(5):1745-1751.

Björklund, Anders, Lindahl, Mikael, and Erik Plug. 2006. The Origins of Intergenerational Associations: Lessons from Swedish Adoption Data. Quarterly Journal of Economics, 121(3): 999-1028.

Black, Sandra E., Devereux, Paul J., and Kjell G. Salvanes. 2005. Why the Apple Doesn't Fall Far: Understanding Intergenerational Transmission of Human Capital. American Economic Review, 95(1):437-449.

Chay, Kenneth Y. and James L. Powell. 2001. Semiparametric Censored Regression Models. Journal of Economic Perspectives, 15(4):29-42.

Goldberger, Arthur S. 1983. Abnormal Selection Bias. In Studies in Econometrics, Time Series, and Multivariate Statistics. S. Karlin et al. eds. New York: Academic Press, 67-84.

Haider, Steven J. and Gary Solon. 2006. Life-Cycle Variation in the Association between Current and Lifetime Earnings. American Economic Review, 96(4):1308-1320.

Oreopoulos, Philip, Page, Marianne E.J., and Ann Huff Stevens. 2006. The Intergenerational Effects of Compulsory Schooling. Journal of Labor Economics Perspectives, 24(4):729-760.

Plug, Erik. 2004. Estimating the Effect of Mother's schooling on Children's Schooling Using a Sample of Adoptees. American Economic Review, 94:358-368.

Sewell, William H., Robert M. Hauser, Kirsten Springer, and Taissa S. Hauser. 2004. As We Age: The Wisconsin Longitudinal Study, 1957-2001. London: Elsevier Ltd. 
Wisconsin Longitudinal Study (WLS). Version 11.0 Preliminary Release: 2004.

Hauser, Robert M; Hauser, Taissa S. Madison, WI: University of WisconsinMadison, WLS; http://www.ssc.wisc.edu/ wls/documentation/.

Wollmering, Erica. 2006. Preliminary Wisconsin Longitudinal Study Handbook (1.10.06) with Contributions by Wisconsin Longitudinal Study Staff. 
Table 1-Means and Standard Deviations of Selected Variables in WLS Samples

\begin{tabular}{|c|c|c|c|c|}
\hline \multirow[b]{2}{*}{ Independent Variable } & \multicolumn{2}{|c|}{ Own Birth Children } & \multicolumn{2}{|c|}{ Adoptees } \\
\hline & Mean & Std. Dev. & Mean & Std. Dev. \\
\hline Completed years of schooling (2004) & 14.37 & 2.28 & 14.03 & 2.09 \\
\hline Observed years of schooling (1992) & 13.84 & 2.34 & 13.25 & 2.12 \\
\hline Expected years of schooling ${ }^{a}(1975)$ & 14.87 & 1.90 & 15.14 & 1.94 \\
\hline Years of schooling mother & 12.83 & 1.65 & 13.27 & 1.92 \\
\hline Gender (daughter) & 0.50 & 0.50 & 0.49 & 0.50 \\
\hline Age (1992) & 26.52 & 4.51 & 23.97 & 4.62 \\
\hline$N$ & 14,524 & & 520 & \\
\hline
\end{tabular}

${ }^{a}$ Parental expectations are asked for only one of the respondent's children. Means and standard deviations are therefore calculated on smaller samples of respectively 4,097 and 52 observations. 
Table 2-Estimates of the Effects of Mother's and Father's Schooling on Own-Birth Children's Schooling.

\begin{tabular}{|c|c|c|c|c|c|c|c|c|c|}
\hline & \multicolumn{3}{|c|}{$\begin{array}{l}\text { Mobility Estimates without } \\
\text { Censoring (WLS 2004) }\end{array}$} & \multicolumn{3}{|c|}{$\begin{array}{l}\text { Mobility Estimates with } \\
\text { Censoring (WLS 1992) }\end{array}$} & \multicolumn{3}{|c|}{ Estimated Differences } \\
\hline & $(1)$ & $(2)$ & (3) & (4) & $(5)$ & (6) & $(7)$ & (9) & $(9)$ \\
\hline Mother's schooling & $\begin{array}{l}0.46^{a} \\
0.01^{* * * b}\end{array}$ & & $\begin{array}{l}0.24 \\
0.02^{* * *}\end{array}$ & $\begin{array}{l}0.41 \\
0.01^{* * *}\end{array}$ & & $\begin{array}{l}0.20 \\
0.02^{* * *}\end{array}$ & $\begin{array}{l}-0.05^{c} \\
0.01^{* * *}\end{array}$ & & $\begin{array}{l}-0.04 \\
0.01^{* * *}\end{array}$ \\
\hline Father's schooling & & $\begin{array}{l}0.34 \\
0.01^{* * *}\end{array}$ & $\begin{array}{l}0.26 \\
0.01^{* * *}\end{array}$ & & $\begin{array}{l}0.31 \\
0.01^{* * *}\end{array}$ & $\begin{array}{l}0.24 \\
0.01^{* * *}\end{array}$ & & $\begin{array}{l}-0.03 \\
0.00^{* * *}\end{array}$ & $\begin{array}{l}-0.02 \\
0.01^{* * *}\end{array}$ \\
\hline $\begin{array}{l}N \\
N^{c}\end{array}$ & & $\begin{array}{c}14,524 \\
0\end{array}$ & & & $\begin{array}{c}14,524 \\
3,278\end{array}$ & & & & \\
\hline \multicolumn{10}{|c|}{ CENSORED REGRESSION MODEL } \\
\hline Mother's schooling & & & & $\begin{array}{l}0.54 \\
0.02^{* * *}\end{array}$ & & $\begin{array}{l}0.29 \\
0.02^{* * *}\end{array}$ & $\begin{array}{l}0.08 \\
0.01^{* * *}\end{array}$ & & $\begin{array}{l}0.05 \\
0.01^{* * *}\end{array}$ \\
\hline Father's schooling & & & & & $\begin{array}{l}0.38 \\
0.01^{* * *}\end{array}$ & $\begin{array}{l}0.29 \\
0.01^{* * *}\end{array}$ & & $\begin{array}{l}0.04 \\
0.00^{* * *}\end{array}$ & $\begin{array}{l}0.03 \\
0.00^{* * *}\end{array}$ \\
\hline $\begin{array}{l}N \\
N^{c}\end{array}$ & & & & & $\begin{array}{c}14,524 \\
3,278\end{array}$ & & & & \\
\hline \multicolumn{10}{|c|}{ CENSORED OBSERVATIONS REPLACED WITH PARENTAL EXPECTATIONS ${ }^{d, e}$} \\
\hline Mother's schooling & $\begin{array}{l}0.45 \\
0.02^{* * *}\end{array}$ & & $\begin{array}{l}0.24 \\
0.02\end{array} * * *$ & $\begin{array}{l}0.45 \\
0.02^{* * *}\end{array}$ & & $\begin{array}{l}0.23 \\
0.02^{* * *}\end{array}$ & $\begin{array}{r}-0.01 \\
0.01\end{array}$ & & $\begin{array}{r}-0.01 \\
0.01\end{array}$ \\
\hline Father's schooling & & $\begin{array}{l}0.35 \\
0.01\end{array}$ *** & $\begin{array}{l}0.27 \\
0.01\end{array}$ *** & & $\begin{array}{l}0.35 \\
0.01^{* * *}\end{array}$ & $\begin{array}{l}0.27 \\
0.01^{* * *}\end{array}$ & & $\begin{array}{l}0.00 \\
0.01\end{array}$ & $\begin{array}{l}0.00 \\
0.01\end{array}$ \\
\hline $\begin{array}{l}N \\
N^{c}\end{array}$ & & $\begin{array}{c}4,097 \\
0\end{array}$ & & & $\begin{array}{c}4,097 \\
874\end{array}$ & & & & \\
\hline \multicolumn{10}{|c|}{ EXCLUDING ALL CHILDREN YOUNGER THAN 25} \\
\hline Mother's schooling & & & & $\begin{array}{l}0.50 \\
0.02^{* * *}\end{array}$ & & $\begin{array}{l}0.26 \\
0.02^{* * *}\end{array}$ & $\begin{array}{l}0.04 \\
0.01^{* * *}\end{array}$ & & $\begin{array}{l}0.03 \\
0.01^{* * *}\end{array}$ \\
\hline Father's schooling & & & & & $\begin{array}{l}0.36 \\
0.01^{* * *}\end{array}$ & $\begin{array}{l}0.28 \\
0.01^{* * *}\end{array}$ & & $\begin{array}{l}0.02 \\
0.01^{* * *}\end{array}$ & $\begin{array}{l}0.02 \\
0.01^{* * *}\end{array}$ \\
\hline $\begin{array}{l}N \\
N^{c}\end{array}$ & & & & & $\begin{array}{c}10,143 \\
508\end{array}$ & & & & \\
\hline
\end{tabular}

${ }^{a}$ All regressions include additional controls or the child's age and gender.

${ }^{b}$ Robust standard errors are in italics; ${ }^{*}$ significant at $10 \%$ level, ${ }^{* *}$ significant at $5 \%$ level, ${ }^{* * *}$ significant at $1 \%$ level.

${ }^{c}$ Estimates come from previous school models using censored and uncensored samples where all coefficients vary by sample status. The interacted schooling estimates represent absolute differences between mobility parameters. Insignificance suggests the absence of structural differences.

${ }^{d}$ Parental expectations are expressed in levels. We convert level into years as follows: less than high school. ..10; high school graduate. ..12; technical and vocational education. ..13; some college...14.5; college graduate. .16; M.A. or M.S. degree...18; Law degree, M.D., D.D.S., D.V.M. degree...19; Ph.D...20.

${ }^{e}$ Samples are smaller because expectations are elicited for only one of the respondent's children. 
Table 3-Estimates of the Effects of Mother's and Father's Schooling on Adopted Children's Schooling.

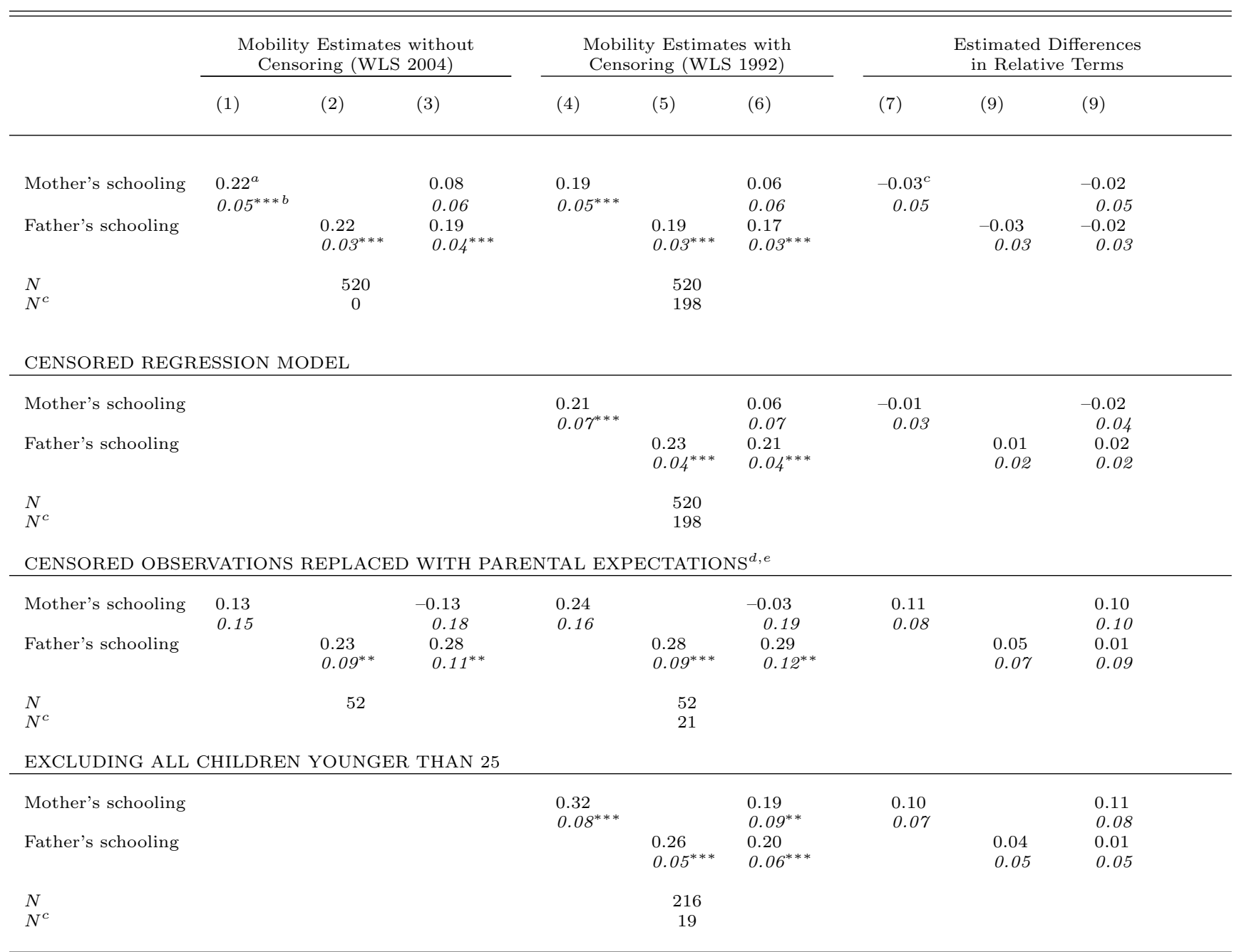

${ }^{a}$ All regressions include additional controls or the child's age and gender.

${ }^{b}$ Robust standard errors are in italics; ${ }^{*}$ significant at $10 \%$ level, ${ }^{* *}$ significant at $5 \%$ level, ${ }^{* * *}$ significant at $1 \%$ level.

${ }^{c}$ Estimates come from previous school models using censored and uncensored samples where all coefficients vary by sample status. The interacted schooling estimates represent absolute differences between mobility parameters. Insignificance suggests the absence of structural differences.

${ }^{d}$ Parental expectations are expressed in levels. We convert level into years as follows: less than high school. ..10; high school graduate...12; technical and vocational education. .13; some college...14.5; college graduate...16; M.A. or M.S. degree...18; Law degree, M.D., D.D.S., D.V.M. degree...19; Ph.D...20.

${ }^{e}$ Samples are smaller because expectations are elicited for only one of the respondent's children. 
Table 4-Estimating the Bias of Replacing Observed with Expected Schooling using Various Censored Samples.

\begin{tabular}{|c|c|c|c|c|c|c|c|c|}
\hline \multirow[b]{2}{*}{ OWN BIRTH CHILDREN } & \multicolumn{8}{|c|}{ Regressing $d_{t} \eta_{t}$ on Parental Schooling using Samples with Increasing Shares of Censoring ${ }^{a}$} \\
\hline & $\begin{array}{r}20-30 \% \\
(1)^{c}\end{array}$ & $\begin{array}{r}30-40 \% \\
(2)\end{array}$ & $\begin{array}{r}40-50 \% \\
(3)^{c}\end{array}$ & $\begin{array}{r}50-60 \% \\
(4)\end{array}$ & $\begin{array}{r}60-70 \% \\
(5)\end{array}$ & $\begin{array}{r}70-80 \% \\
(6)\end{array}$ & $\begin{array}{r}80-90 \% \\
(7)\end{array}$ & $\begin{array}{l}100 \% \\
(8)\end{array}$ \\
\hline $\begin{array}{l}\text { Mother's schooling } \\
\text { Father's schooling }\end{array}$ & $\begin{array}{r}-0.01 \\
0.01^{b} \\
0.00 \\
0.01\end{array}$ & $\begin{array}{r}-0.02 \\
0.01 \\
-0.01 \\
0.01\end{array}$ & $\begin{array}{r}-0.03 \\
0.02 \\
-0.02 \\
0.01^{*}\end{array}$ & $\begin{array}{r}-0.03 \\
0.02 \\
-0.02 \\
0.01^{*}\end{array}$ & $\begin{array}{r}-0.03 \\
0.02 \\
-0.02 \\
0.01^{*}\end{array}$ & $\begin{array}{l}-0.04 \\
0.02^{*} \\
-0.03 \\
0.01^{*}\end{array}$ & $\begin{array}{l}-0.05 \\
0.02^{* *} \\
-0.03 \\
0.01^{* *}\end{array}$ & $\begin{array}{l}-0.06 \\
0.02^{* * *} \\
-0.04 \\
0.02^{* * *}\end{array}$ \\
\hline $\begin{array}{l}N \\
N^{c}\end{array}$ & $\begin{array}{r}4097 \\
874\end{array}$ & $\begin{array}{l}4097 \\
1285\end{array}$ & $\begin{array}{l}4097 \\
1712\end{array}$ & $\begin{array}{l}4097 \\
2280\end{array}$ & $\begin{array}{l}4097 \\
2859\end{array}$ & $\begin{array}{l}4097 \\
3157\end{array}$ & $\begin{array}{l}4097 \\
3388\end{array}$ & $\begin{array}{l}4097 \\
4097\end{array}$ \\
\hline ADOPTEES & & & & & & & & \\
\hline $\begin{array}{l}\text { Mother's schooling } \\
\text { Father's schooling }\end{array}$ & & & $\begin{array}{l}0.10 \\
0.13 \\
0.01 \\
0.08\end{array}$ & $\begin{array}{l}0.16 \\
0.15 \\
0.06 \\
0.10\end{array}$ & $\begin{array}{l}0.21 \\
0.17 \\
0.07 \\
0.11\end{array}$ & $\begin{array}{l}0.13 \\
0.19 \\
0.12 \\
0.12\end{array}$ & $\begin{array}{r}-0.02 \\
0.21 \\
0.15 \\
0.13\end{array}$ & $\begin{array}{r}0.23 \\
0.22 \\
-0.02 \\
0.14\end{array}$ \\
\hline $\begin{array}{l}N \\
N^{c}\end{array}$ & & & $\begin{array}{l}52 \\
21\end{array}$ & $\begin{array}{l}52 \\
30\end{array}$ & $\begin{array}{l}52 \\
36\end{array}$ & $\begin{array}{l}52 \\
40\end{array}$ & $\begin{array}{l}52 \\
45\end{array}$ & $\begin{array}{l}52 \\
52\end{array}$ \\
\hline
\end{tabular}

${ }^{a}$ All regressions include additional controls or the child's age and gender.

${ }^{b}$ Standard errors are in italics; ${ }^{*}$ significant at $10 \%$ level, ${ }^{* *}$ significant at $5 \%$ level, ${ }^{* *}$ significant at $1 \%$ level.

${ }^{c}$ This column corresponds to the true percentage of censored observations as observed in 1992 (21.33 and 40.38 percent for own birth children and adoptees, respectively). 
Figure 1: Difference between Expected and Completed Schooling Seperately for Own Birth Children (left) and Adoptees (right)
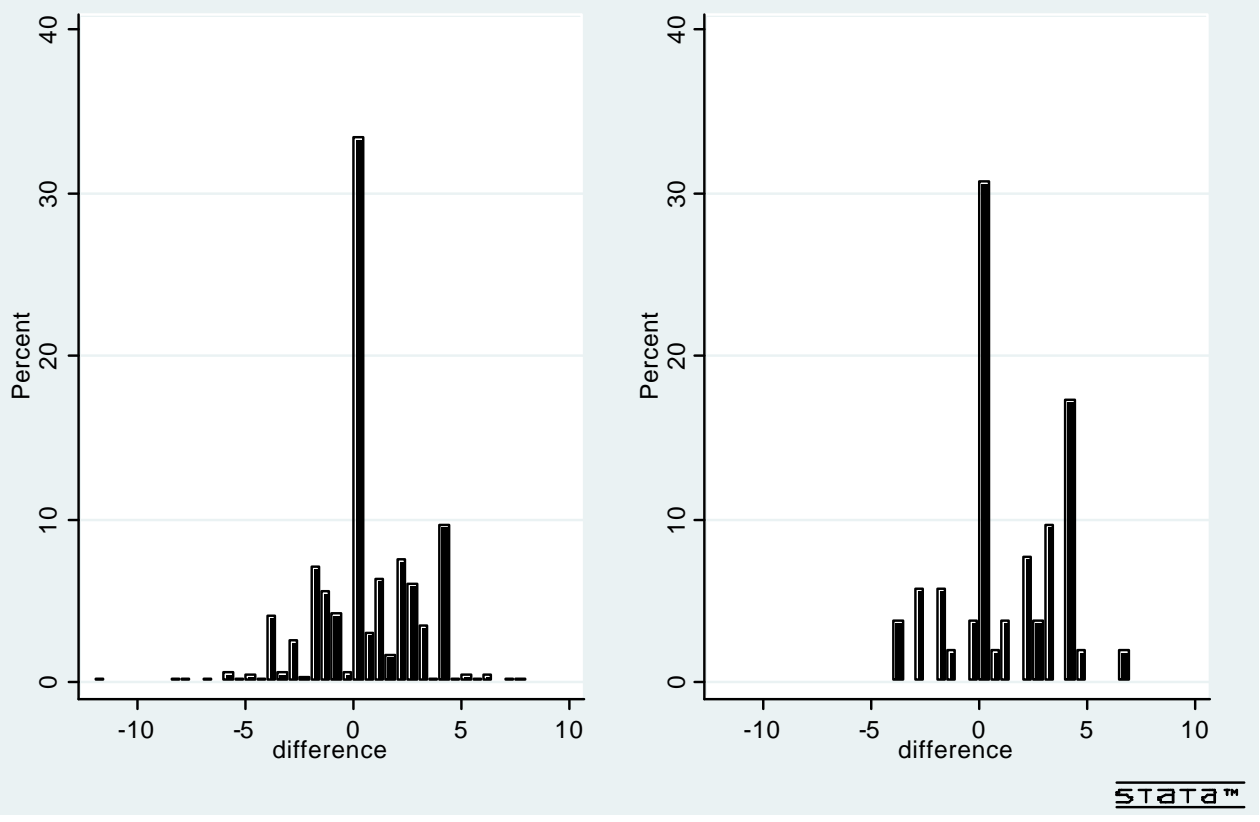